\title{
Transcranial Magnetic Stimulation Dissociates Prefrontal and Parietal Contributions to Task Preparation
}

\author{
(D) Paul S. Muhle-Karbe, ${ }^{1}$ Michael Andres, ${ }^{1,2}$ and Marcel Brass ${ }^{1}$ \\ ${ }^{1}$ Department of Experimental Psychology, Ghent University, 9000 Ghent, Belgium, and ${ }^{2}$ Psychological Sciences Research Institute, Université catholique de \\ Louvain, 1348 Louvain-la-Neuve, Belgium
}

Cognitive control is thought to rely upon a set of distributed brain regions within frontoparietal cortex, but the functional contributions of these regions remain elusive. Here, we investigated the disruptive effects of transcranial magnetic stimulation (TMS) over the human prefrontal and parietal cortices in task preparation at different abstraction levels. While participants completed a task-switching paradigm that assessed the reconfiguration of task goals and response sets independently, TMS was applied over the left inferior frontal junction (IFJ) and over the left intraparietal sulcus (IPS) during task preparation. In Experiment 1, TMS over the IFJ caused interference with the updating of task goals, while leaving the updating of response sets unaffected. In Experiment 2, TMS over the IPS created the opposite pattern of results, perturbing only the ability to update response sets, but not task goals. Experiment 3 furthermore revealed that TMS over the IPS interfered with task goal updating when the pulses are delivered at a later point in time during preparation. This dissociation of abstract and action-related components not only reveals distinct cognitive control processes during task preparation, but also sheds new light on how prefrontal and parietal areas might work in concert to support flexible and goal-oriented control of behavior.

Key words: cognitive control; parietal cortex; prefrontal cortex; task preparation; transcranial magnetic stimulation

\section{Introduction}

Task preparation has been shown to rely upon a set of distributed regions within frontoparietal cortex that are typically located around the inferior frontal junction (IFJ) and the intraparietal sulcus (IPS; for review, see Ruge et al., 2013). Although the general involvement of these areas in preparatory control is well established, their respective contributions remain much debated.

Classical theories of cognitive control ascribe a superordinate role to the prefrontal cortex (PFC), which is thought to generate top-down signals to bias processing in posterior cortices (Miller and Cohen, 2001; Bunge and Wallis, 2008; Fuster, 2008; Passingham and Wise, 2012). This view is anatomically plausible given the PFC's rich connections with other association cortices, and is furthermore supported by chronometric evidence of prefrontal activity preceding parietal activity during task preparation in macaques (Merchant et al., 2011; Goodwin et al., 2012; Crowe et al., 2013) and humans (Brass et al., 2005; Jamadar et al., 2010). At the functional level, neuroimaging studies have revealed very similar properties of prefrontal and parietal areas in cognitive control

\footnotetext{
Received Nov. 25, 2013; revised July 31, 2014; accepted Aug. 7, 2014.

Author contributions: P.S.M.-K., M.A., and M.B. designed research; P.S.M.-K. performed research; P.S.M.-K. analyzed data; P.S.M.-K. and M.A. wrote the paper.

P.S.M.-K. and M.B. were supported by Grant B/09019/02 of the Flemish Research Foundation. M.A. is a research associate at the FRS-FNRS (Belgium). We thank Pieter Vandemaele for assistance with the acquisition of MR images, Patrick Santens for support with the screening of participants, and Maggie Lynn and two anonymous reviewers for helpful comments on the paper.

The authors declare no competing financial interests.

Correspondence should be addressed to Paul S. Muhle-Karbe, Department of Experimental Psychology, Ghent University, Henri Dunantlaan 2, B-9000 Ghent, Belgium. E-mail: paulsimon.muhlekarbe@ugent.be.

DOI:10.1523/JNEUROSCI.4931-13.2014

Copyright $\odot 2014$ the authors $\quad 0270-6474 / 14 / 3412481-09 \$ 15.00 / 0$
}

(Woolgar et al., 2011). Nevertheless, several studies demonstrated dissociations, implicating a rather general role of the IPS in sensorimotor transformations, and a more specific contribution of the IFJ to the guidance of behavior on the basis of internal goals (Bunge et al., 2002; Hartstra et al., 2011; Philipp et al., 2013). Together, these findings indicate that the IFJ and the IPS may both represent upcoming task demands, but at different abstraction levels. While the IFJ may provide an initial representation of the general context of a task episode, the IPS might specify the resulting mappings of stimulus categories to effectors, thereby providing a more action-related task representation (Brass and von Cramon, 2004; Brass et al., 2005).

Despite support from diverse areas of inquiry, the evidence for this top-down view on preparatory control is still rather indirect and alternative ideas have been raised in the literature. For instance, it has been argued that the IPS constitutes the source rather than the target of task-related control signals (Bode and Haynes, 2009; Swaminathan and Freedman, 2012). Others have proposed that frontoparietal areas serve similar rather than hierarchically organized functions (Dehaene et al., 1998; Duncan, 2010). Correlational methods, such as functional neuroimaging, are insufficient to resolve this ambiguity, as they cannot reveal whether task-related brain activity in a given region is in fact necessary for the respective behavior (Walsh and Cowey, 2000). Here, we sought to overcome this limitation by investigating the disruptive effects of transcranial magnetic stimulation (TMS) over the IFJ and the IPS at different levels of task preparation. TMS was applied over the left IFJ and over the left IPS while participants completed a modified task-switching paradigm that independently assessed updating of either abstract task goals or different response sets within a single task. According to top- 
A

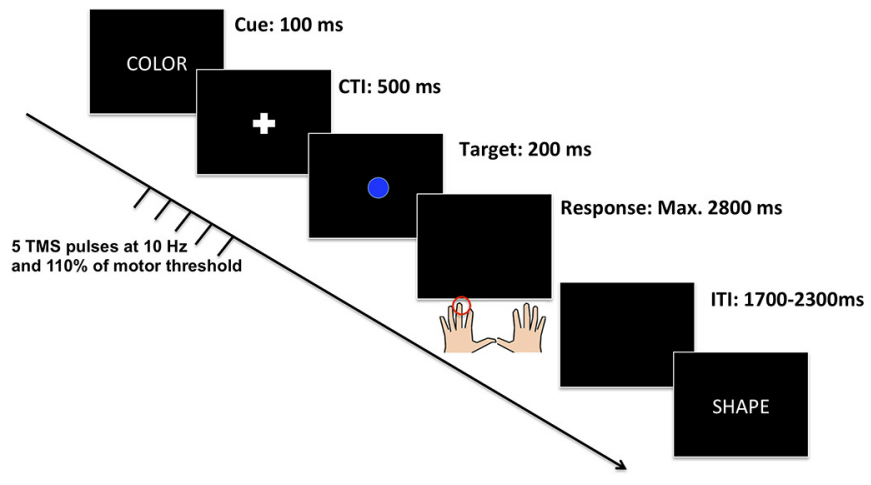

B

Task Goal Block with ring fingers

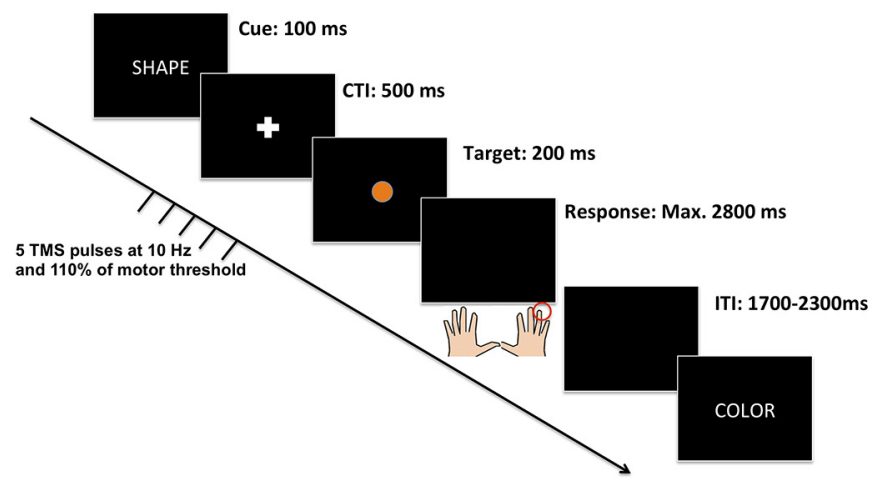

Response Set Block with color categorization

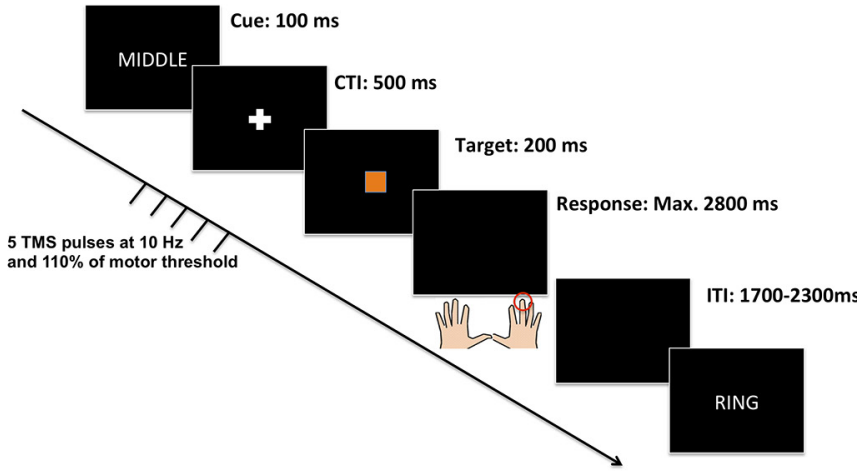

Response Set Block with shape categorization

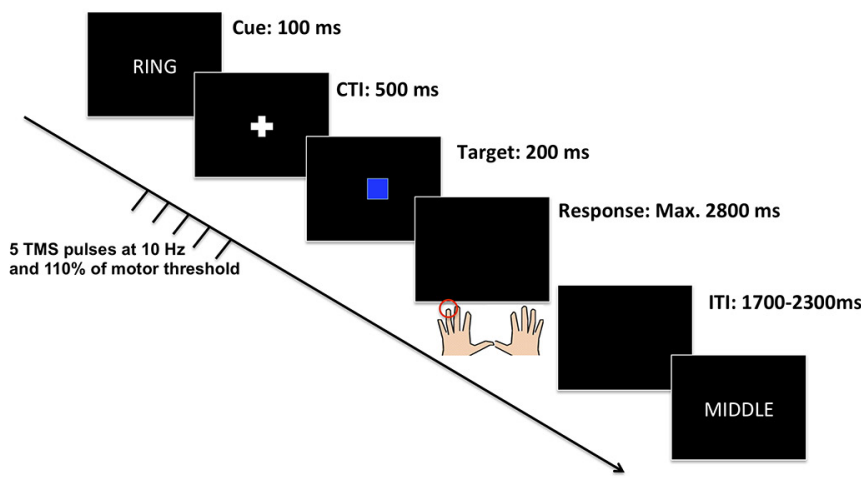

Figure 1. Single-trial structure of the different block types used in Experiments 1 and 2. In TGBs (left), stimuli were classified according to two different categorization rules (shape or color) that could repeat or alternate across trials. In the shape task, participants were instructed to respond with the left hand to a square and with the right hand to a circle. In the color task, participants were instructed to respond with the left hand to a blue stimulus and with the right hand to an orange stimulus. Half of the blocks were performed with the left and right middle fingers $(\boldsymbol{A})$ and the other half with the left and right ring fingers (B). In RSBs (right), stimuli were classified according to only one of the categorization rules, but the response set used for task implementation (middle fingers or ring fingers) could repeat or alternate across trials. Half of the blocks required color categorization ( $\boldsymbol{C}$, and the other half classification of shape $(\boldsymbol{D})$. Note: Red circles indicate the correct responses in each of the examples.

down theories, prefrontal TMS should interfere only with the capacity to update task goals, but not response sets, whereas parietal TMS should yield the opposite interference pattern.

\section{Materials and Methods}

Participants. The sample consisted of 45 right-handed males (mean age $=23.04 ; \mathrm{SD}=2.37$; range, $19-28)$ that were divided across the three experiments (number of participants: Experiment $1=14$, Experiment $2=14$, Experiment $3=17$ ). All participants reported normal or corrected-to-normal vision and had no personal or family history of neurological abnormalities. An additional screening procedure was conducted to exclude the presence of other TMS contraindications (Rossi et al., 2009). All subsequent procedures were approved by the local ethics committee and written informed consent was received from all participants prior to participation.

Stimuli and tasks. We assessed abstract and action-related components of task preparation in separate block types using a modified version of the cued task-switching paradigm (Philipp et al., 2013 for a similar procedure). Task-goal blocks (TGBs) required subjects to classify stimuli according to two different categorization rules (shape vs color) that could repeat or alternate across trials. Half of these blocks were performed with the middle fingers (left and right) and the other half with the ring fingers (left and right). TGBs thus required an occasional reconfiguration of the relevant task goal, whereas the response set used for task implementation remained constant throughout the block. Conversely, response-set blocks (RSBs) required subjects to apply only a single categorization rule throughout the entire block. Half of these blocks required categorization of color, and the other half categorization of shape. In these blocks, however, the response set (middle fingers vs ring fingers) could repeat or alternate across trials. RSBs thus required an occasional update of the relevant implementation rules, whereas the abstract goal of the task remained constant throughout the entire block. Note that in TGBs half of the trials were congruent (i.e., the target stimulus was associated with the same response in both tasks) and the other half incongruent (i.e., the target stimulus was associated with different responses in the two tasks). In RSBs, on the other hand, stimuli were always univalent because they were categorized only based on one stimulus feature throughout the block. However, as congruency did not interact with the stimulated brain region in any of the three experiments, data in TGBs were pooled across congruent and incongruent trials.

The trial structure of TGBs and RSBs is illustrated in Figure 1. All stimuli were presented centrally on a black screen. Trials began with the presentation of a task cue for $100 \mathrm{~ms}$. In TGBs, the words "KLEUR" or "VORM" (Dutch for "color" and "shape") were displayed (font = Arial, color $=$ white, font size $=40)$ to instruct color or shape categorization respectively. In RSBs, the words "MIDDEL" or "RING" (Dutch for "middle" and "ring") instructed responses with the middle fingers or the ring fingers respectively. This was followed by a cue-target interval (CTI) of $500 \mathrm{~ms}$ during which a fixation cross $($ size $=0.5 \mathrm{~cm}$, color $=$ white) was shown. Thereafter a target stimulus was presented on the screen for 200 ms. Targets were either squares or circles ( $2 \mathrm{~cm}$ diameter), and presented in either blue or orange color (matched for luminance). After the target 
A
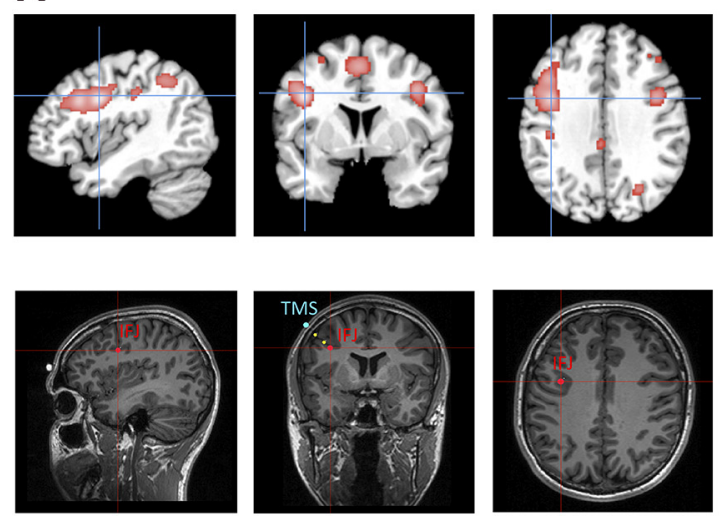

B
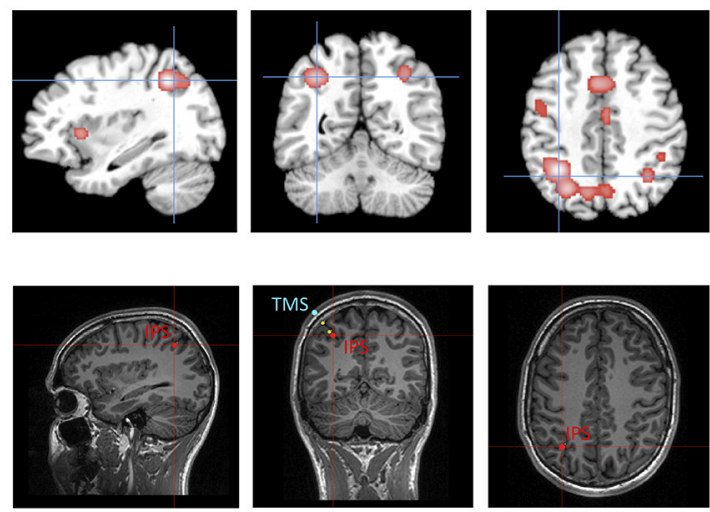

Figure 2. Illustration of the TMS navigation in Experiments $1(\boldsymbol{A})$ and $2(\boldsymbol{B})$, based on the results of a meta-analysis of 45 cued task-switching experiments. In the top row, results of the meta-analysis are overlaid on the template of the Montreal Neurological Institute. The peak coordinates of the meta-analysis, displayed in red at the bottom, were used as a guide for positioning the coil over the IFJ $(-40,4,30)$ and the IPS $(-34,-56,43)$ by means of frameless stereotaxic neuronavigation. The coronal sections of the bottom also display the position of the coil center, where the magnetic field is maximal, relative to the subject's skull (blue markers). Yellow spheres indicate the direction of the current flow (distance between two spheres $=1 \mathrm{~cm}$ ). The average distance between the skull and the target site across participants was $2.36 \mathrm{~cm}$ in Experiment 1, and $2.45 \mathrm{~cm}$ in Experiment 2. Note that the application of TMS trains also affects the brain tissue between the skull and the target site.

disappeared from the screen, participants were given a time window of $2800 \mathrm{~ms}$ to respond. Trials were separated by an intertrial interval of jittered duration (1700-2300 ms) during which a blank screen was presented. Subjects" responses were recorded with the buttons "A," "S," "K," and "L," of a QWERTY keyboard. Instructions emphasized speed and accuracy of performance equally.

The full combination of task goals and response sets resulted in four different blocks (i.e., TGB with middle fingers, TGB with ring fingers, RSB with color categorization, RSB with shape categorization; Fig. 1). TGBs counted 36 trials during which both task goals were instructed equally often; RSB counted 36 trials during which both response sets were instructed equally often. Moreover, in each block, task goals or response sets were repeated in two-thirds of all trials (repetition trials) and alternated in one-third of all trials (switch trials). Stimulus presentation was counterbalanced to ensure that each target and each response occurred equally often across design cells and to guarantee an equivalent frequency of stimulus repetitions and response repetitions across blocks and design cells.

Overall, participants performed two runs (corresponding to different stimulation sites see below), each of which contained all four blocks, resulting in a total of 288 experimental trials. The two runs were separated by a break of $\sim 30 \mathrm{~min}$. Block order was counterbalanced across subjects with the constraint that TGBs and RSBs always alternated (to minimize the effects of continuous influences, such as fatigue). Within each participant, the block order was kept identical across the two runs. In advance of each block, participants received instructions and performed a practice block of six trials. In Experiment 3, this procedure was modified. Each run consisted of four TGBs and all blocks were performed with the middle fingers (see Results, Experiment 3 for details).

TMS navigation. The positioning of the TMS coil was guided by a neuronavigation system in which target sites were located onto individual anatomical MR images acquired in a separate session before the TMS experiment. To identify coordinates of subregions within the prefrontal and parietal cortices that are implicated in task preparation, we conducted a quantitative meta-analysis of brain imaging studies using the activation-likelihood estimation (ALE)-method (Eickhoff et al., 2009, 2012). The ALE-method, as implemented in GingerALE software (brainmap.org/ale), provides a quantitative voxelwise approach for meta-analyses of neuroimaging data. Its central concept is to treat foci of single studies as spatial probability distributions rather than as single coordinates. To reveal statistically significant clustering of brain activity, ALE-maps are generated by computing the voxelwise concordance of activation across experiments and compared with a random distribution, which is based on permutation tests. Studies for the meta-analysis were selected based on the following criteria: (1) fMRI was used as the brainimaging method, (2) coordinates were reported in a standardized stereotaxic space and statistical analyses were applied to the whole brain, (3) study samples consisted of healthy adults, and (4) studies used a cued task-switching paradigm and the analysis entailed at least one contrast of cue-related brain activation on switch trials compared with repetition trials. Altogether, we identified 45 studies including 817 participants that fulfilled these criteria and entered the 469 foci that were reported in the selected contrasts to the meta-analysis. The false discovery rate of the analysis was set to $p<0.01$ and the cluster threshold to a minimum of 200 contiguous voxels. This analysis revealed significant concordance of activation within bilateral frontolateral, insular, frontomedian, and intraparietal areas, closely corresponding to previous descriptions of frontoparietal areas that are involved in diverse types of cognitive demand (Cole and Schneider, 2007; Duncan, 2010). Most importantly for the given purpose, the two clusters with the greatest ALE-values were located within the left IFJ (MNI peak coordinate: -40, 4, 32), and the left IPS (MNI peak coordinate: $-34,-56,43)$. In a second step, these normalized coordinates were transformed into each individual's native space with a reversed normalization procedure, to allow the precise positioning of the TMS coil over the target region using the Brainsight frameless stereotaxic software (Rogue Research). Figure 2 illustrates the location of both target sites within standardized and native coordinate spaces. The somatosensory leg area was chosen as control site because it is not involved in task preparation. To localize this area in each subject, the stimulator coil was placed over the interhemispheric midline and moved caudally beyond the central sulcus. The resulting MNI coordinates (Experiment 1: 0, -39, 76; Experiment 2: $-1,-39,73$; Experiment 3: 0, $-38,71)$ confirmed close correspondence to anatomical locations of the somatosensory leg area reported in previous studies (Ruben et al., 2001; Del Gratta et al., 2002).

TMS protocol. Repetitive TMS was delivered with a Magstim Rapid stimulator (Magstim Company) using a figure-eight coil (inner diameter $=70 \mathrm{~mm}$ ). In each trial, a train of five TMS pulses was delivered at a frequency of $10 \mathrm{~Hz}$ and an intensity corresponding to $110 \%$ of each participant's resting motor threshold (mean output $=64.2 \%$, range, 56-65). Electromyographical recordings (BioSemi) were used to measure the resting motor threshold, defined as the minimum intensity necessary to induce motor-evoked potentials with a peak-to-peak amplitude $>50 \mu \mathrm{V}$ in the first dorsal interosseous muscle of the right hand in at least 5 of 10 trials. In one run of four blocks, the coil was positioned over the target site (IFJ in Experiment 1, and IPS in Experiments 2 and 3), and in the other run over the control site (CTR). The sequence of the stimulation sites (target site vs control site) was counterbalanced across subjects. In Experiments 1 and 2, TMS trains were time-locked to the offset of the task cue and thus covered the first $400 \mathrm{~ms}$ of the CTI. The trains were applied after presentation of the task cue and before onset of a target stimulus to maximize interference with the processes involved in task preparation while avoiding nonspecific effects upon perceptual process- 
A

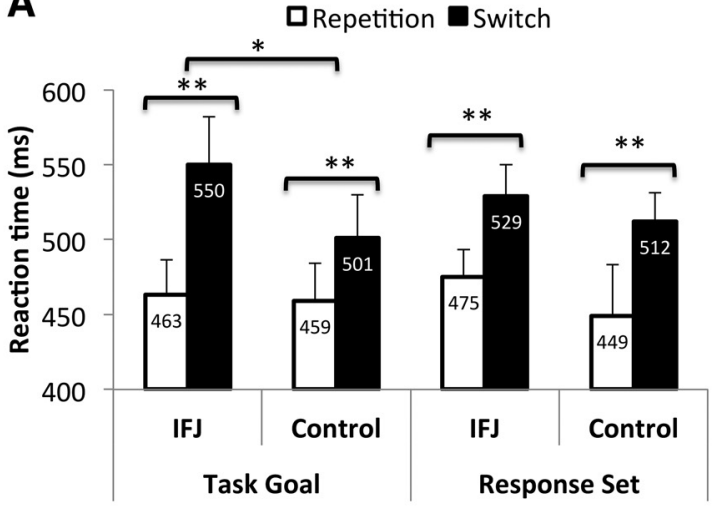

B

QRepetition $\mathbf{B}$ sitch

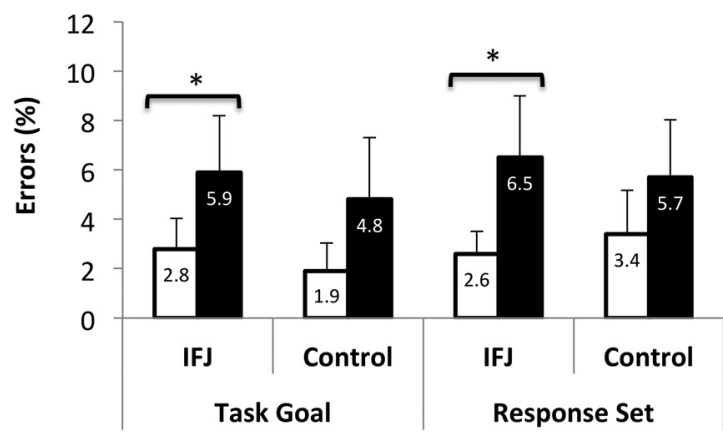

Repetition $\mathbf{S w i t c h}$
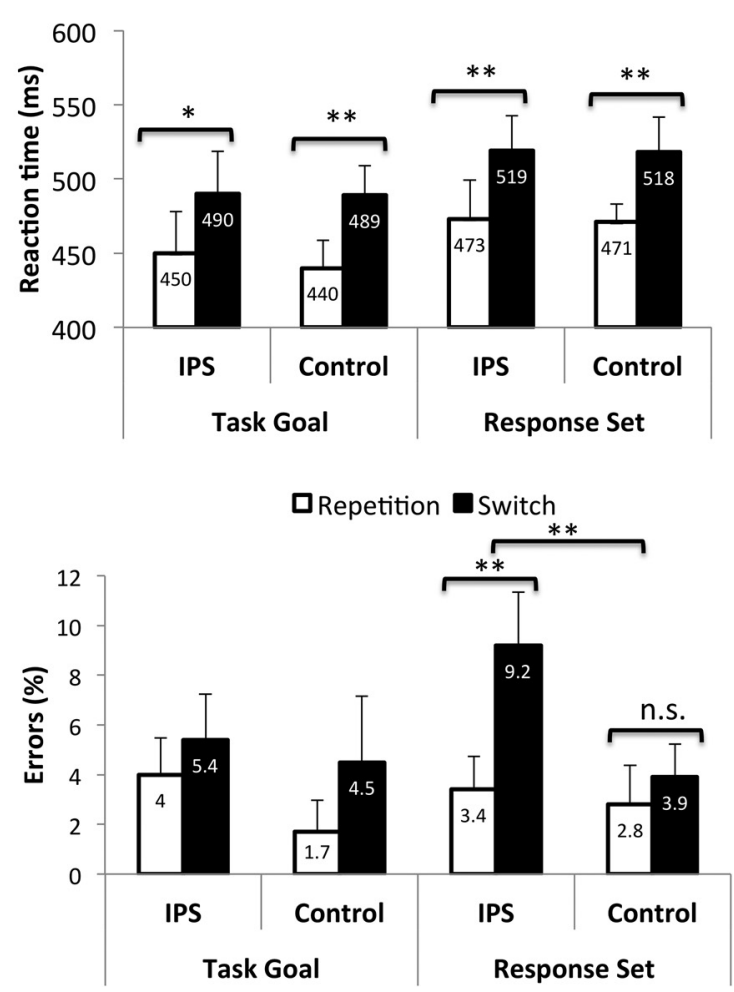

Figure 3. Reaction times $(\boldsymbol{A})$ and error rates $(\boldsymbol{B})$ of Experiments 1 (left) and 2 (right) as a function of the target site, block type, and trial transition. Note: The displayed values are means and within-subject confidence intervals (calculated according to Loftus and Massen, 1994). Asterisks indicate significant differences between repetition and switch trials, as well as differences in switch costs between target and control site stimulation.

ing of the cue or the initiation of a specific response. In Experiment 3, we aimed at probing the involvement of the IPS in the final stages of task goal updating (based on the results of Experiments 1 and 2). Accordingly, in this experiment, the TMS trains were time-locked to the onset of the target stimulus. Moreover, to avoid stimulation during the response period, the number of pulses in each TMS train was reduced from five to three in Experiment 3 (see Fig. 5; see Results, Experiment 3 for details).

Statistical analyses. Individual median reaction times (RTs) and percentages of errors were subjected to repeated-measures ANOVAs with the factors STIMULATION SITE (target site vs control site), BLOCK TYPE (TGB vs RSB), and TRANSITION (repetition vs switch). Error trials and posterror trials (i.e., trials subsequent to errors) were removed from the RT analysis. To assess cognitive interference related to updating, we computed "switch costs" (i.e., the performance difference between switch trials and repetition trials) separately for each block type and target site (Monsell, 2003). To ensure a sufficient level of aggregation for each experimental condition, the data were pooled across left and right hand responses in all subsequent analyses. Based on our assumption that the IFJ is involved in the setting of task goals, and the IPS in the specification of action rules, we expected that TMS would have distinct effects on performance at the level of switch costs. Whereas TMS over the IFJ should enhance switch costs in TGBs but not in RSBs, TMS over the IPS should produce the converse pattern with increased switch costs in RSBs but not in TGBs. Paired-samples $t$ tests were used to perform these planned comparisons between the switch costs in TGBs and in RSBs (one-tailed, $p<0.05$ corrected for multiple comparisons using Bonferroni correction).

\section{Results}

Experiment 1: selective role of the left IFJ in updating task goals

As expected, participants responded slower on switch trials than on repetition trials, as indicated by a significant main effect of
TRANSITION $\left(F_{(1,13)}=19.247, p=0.001\right.$; repetition $=461 \mathrm{~ms}$, switch $=523 \mathrm{~ms})$. The other main effects of STIMULATION SITE and BLOCK TYPE were both nonsignificant as were all two-way interactions. Most importantly, there was a significant three-way interaction between STIMULATION SITE, BLOCK TYPE, and TRANSITION $\left(F_{(1,13)}=5.239, p=0.039\right)$. Planned comparisons revealed that, compared with TMS over the control site, stimulation of the IFJ increased switch costs in TGBs $\left(t_{(13)}=\right.$ 2.813 , corrected $p=0.015$; switch costs: $\mathrm{IFJ}=87 \mathrm{~ms} ; \mathrm{CTR}=42$ $\mathrm{ms})$, but not in $\operatorname{RSBs}\left(t_{(13)}=-0.493\right.$, corrected $p=0.630$; switch costs: IFJ $=52 \mathrm{~ms}$; CTR $=63 \mathrm{~ms}$ ). At the accuracy level, there was only a significant effect of TRANSITION, reflecting the presence of switch costs $\left(F_{(1,13)}=26.16, p=0.0001\right.$; repetition $=2.52 \%$; switch $=5.88 \%)$. All other main effects and interaction terms were nonsignificant (Fig. 3).

\section{Experiment 2: selective role of the left IPS in updating response sets}

Participants responded slower on switch trials than on repetition trials, as indicated by the significant main effect of TRANSITION $\left(F_{(1,13)}=19.36, p=0.001\right.$; repetition $=458 \mathrm{~ms}$, switch $=504$ $\mathrm{ms})$. Moreover, a significant main effect of BLOCK TYPE was found, reflecting that RTs were slower in RSBs than in TGBs $\left(F_{(1,13)}=6.06, p=0.029 ;\right.$ TBGs $=467 \mathrm{~ms}$; RSBs $\left.=495 \mathrm{~ms}\right)$. Importantly, however, the switch costs did not differ between block types or between stimulation sites (both $F$ values $<0.2$ ). No other main effects or interaction terms were significant at the RT level (Fig. 3). The analysis of error rates yielded a significant main effect of TRANSITION, reflecting the presence of switch costs $\left(F_{(1,13)}=9.38, p=0.009\right.$; repetition $=2.99 \%$; switch $\left.=5.73 \%\right)$. 
In addition, the main effect of STIMULATION SITE was significant, indicating increased error rates after IPS stimulation $\left(F_{(1,13)}=7.30, p=0.018\right.$; IPS $=5.51 \%$; CTR $\left.=3.21 \%\right)$. Importantly, this effect was further qualified by a significant three-way interaction between STIMULATION SITE, BLOCK TYPE, and TRANSITION $\left(F_{(1,13)}=5.96, p=0.030\right)$. Planned comparisons revealed that, compared with TMS over the control site, IPS stimulation enhanced switch costs in RSBs $\left(t_{(13)}=3.13\right.$, corrected $p=$ 0.008 ; switch costs: IPS $=5.84 \%$, CTR $=1.09 \%)$, but not in TGBs $\left(t_{(13)}=-0.68\right.$, corrected $p=0.509$; switch costs: IPS $=$ $1.32 \% ;$ CTR $=2.76 \%)$.

We conducted an additional follow-up analysis to further explore the specificity of the observed TMS effect in RSBs. Here, we were interested in the specific types of errors that were consecutive to the IPS stimulation. Given that in RSBs the classification rule remained the same throughout the entire block (e.g., to respond with the left hand to a square and with the right hand to a circle), the selection of task goals and the selection of response sets are reflected independently in the choice of response hand and finger type respectively. As a consequence, we distinguished between three different types of errors. First, set-selection errors were defined as responses with the incorrect finger type of the correct hand. These errors should reflect a specific failure at the level of response-set selection, as the superordinate task rule, which determines the hand choice, was applied correctly. Second, goal-selection errors were defined as responses with the correct finger type of the incorrect hand. These errors indicate the converse type of failure, as they reflect selection of the adequate response set, but an incorrect application of the general categorization rule. Finally, combination errors were defined as responses with the incorrect finger type of the incorrect hand. These errors reflect a simultaneous failure of both processing stages. Based on our prior assumption that the IPS is involved in the specification of action rules, we expected TMS to specifically increase the frequency of set-selection errors when an update of the response set was required. To address this question, we analyzed the percentages of each error type separately using repeated-measures ANOVAs with the factors STIMULATION SITE and TRANSITION. The contribution of an error type to the observed TMS effect on the capacity to update response sets should be reflected in a significant interaction of the two factors. Given the explorative nature of this analysis and the specificity of the prediction tested here, the subsequent analyses are based on one-tailed significance tests without correction for multiple comparisons.

Combination errors hardly ever occurred throughout the entire experiment (only in $0.31 \%$ of repetition trials in blocks with control stimulation) and were thus not analyzed further. For goalselection errors, there was a reliable effect of STIMULATION SITE $\left(F_{(1,13)}=7.823, p=0.015\right)$, reflecting a higher frequency with IPS stimulation $(\mathrm{IPS}=2.96 \%$; CTR $=1.68 \%)$. However, neither the effect of TRANSITION $\left(F_{(1,13)}=0.02, p=0.885\right)$ nor the interaction between STIMULATION SITE and TRANSITION reached significance $\left(F_{(1,13)}=0.36, p=0.561\right)$. This indicates that goal-selection errors, albeit more frequent with IPS stimulation, did not drive the modulation of switch costs observed in the main analysis. Finally, the analysis of set-selection errors yielded significant main effects of STIMULATION SITE $\left(F_{(1,13)}=3.92\right.$, $p=0.035$; IPS $=3.23 \%$, CTR $=1.50 \%)$; and TRANSITION $\left(F_{(1,13)}=10.02 ; p=0.0035\right.$; repetition $=0.70 \%$; switch $=$ $4.03 \%)$, and, most importantly, a significant interaction of the two factors $\left(F_{(1,13)}=4.476, p=0.027\right)$. As predicted, compared with the stimulation of the control site, TMS over the IPS increased the percentages of set-selection errors exclusively on switch trials $\left(t_{(13)}=2.155, p=0.025\right.$; IPS $=5.68 \%$; CTR $=$ $2.38 \%)$, and not on repetition trials $\left(t_{(13)}=0.29, p=0.388\right.$; IPS $=$ $0.78 \%$; CTR $=0.66 \%)$. This pattern of results corroborates the finding that TMS over the IPS increased switch costs in RSBs by enhancing the probability of responding with the no longer adequate response set when an update thereof was required.

\section{Comparison between Experiments 1 and 2}

Although the previous analyses yielded striking differences between the interference effects with prefrontal and parietal TMS, a claim of distinct functions requires a direct statistical comparison between the respective effects in a conjunctive analysis (Nieuwenhuis et al., 2011). However, this is complicated by the fact that TMS affected performance at the level of speed in Experiment 1 and at the level of accuracy in Experiment 2. We therefore computed inverse efficiency scores (IES) to obtain an integrated performance measure across the two experiments (Townsend and Ashby, 1983). IES of all 28 participants were computed individually by dividing the RTs of each design cell by the percentage of correct responses. These scores were subjected to a repeatedmeasures ANOVA using STUDY as a between-subjects factor and STIMULATION SITE, BLOCK TYPE, and TRANSITION as within-subjects factors. A modulation of the respective TMS effects on switching performance by the stimulated target site should be reflected in a significant four-way interaction. The analysis yielded a significant main effect of TRANSITION, reflecting performance costs on switch trials compared with repetition trials $\left(F_{(1,26)}=46.266, p=0.0001\right.$; repetition $=474 \mathrm{~ms}$; switch $=547 \mathrm{~ms})$. In addition, there was a significant four-way interaction between STUDY, STIMULATION SITE, BLOCK TYPE, and TRANSITION $\left(F_{(1,26)}=4.863, p=0.036\right)$. All other main effects and interaction terms were nonsignificant (Fig. 4). To specify the nature of this interaction, we conducted further post hoc comparisons between the "relative switch costs" (i.e., the difference in the magnitude of switch costs with stimulation of the target site and the control site) of the two experiments. In TGBs, relative switch costs were significantly larger in Experiment 1 than in Experiment $2\left(t_{(26)}=2.450\right.$; corrected $p=0.019$; $\mathrm{IFJ}=50 \mathrm{~ms}$; IPS $=-13 \mathrm{~ms}$ ). In RSBs, relative switch costs were numerically larger in Experiment 2 than in Experiment 1, yet this difference did not reach statistical significance $\left(t_{(26)}=1.255\right.$; corrected $p=0.236$; IFJ $=1 \mathrm{~ms}$; IPS $=31 \mathrm{~ms}$ ). The latter may reflect that the computation of IES increases the amount of error variance (Bruyer and Brysbaert, 2011).

\section{Experiment 3: role of the IPS in the final stages of task goal updating}

We conducted a third experiment to further elaborate on the role of the IPS in preparatory control. Given our assumption that this region translates abstract task goals into response sets, we had expected parietal TMS to cause interference with updating primarily in RSBs, which is precisely what was found in Experiment 2. However, the complete absence of interference in TGBs was nevertheless unexpected to us because updating of task goals presumably also necessitates a recoding of the relevant stimulusresponse (SR) rules, in addition to more abstract processes, such as attention shifts between different stimulus dimensions. A possible explanation for this nonfinding resides in the temporal dependence between abstract and action-related preparatory processes. The activation of response sets is typically assumed to take place upon completion of task goal setting (Rubinstein et al., 2001). Accordingly, it seems plausible that in TGBs the CTI is used primarily for goal setting, and response-set activation might 


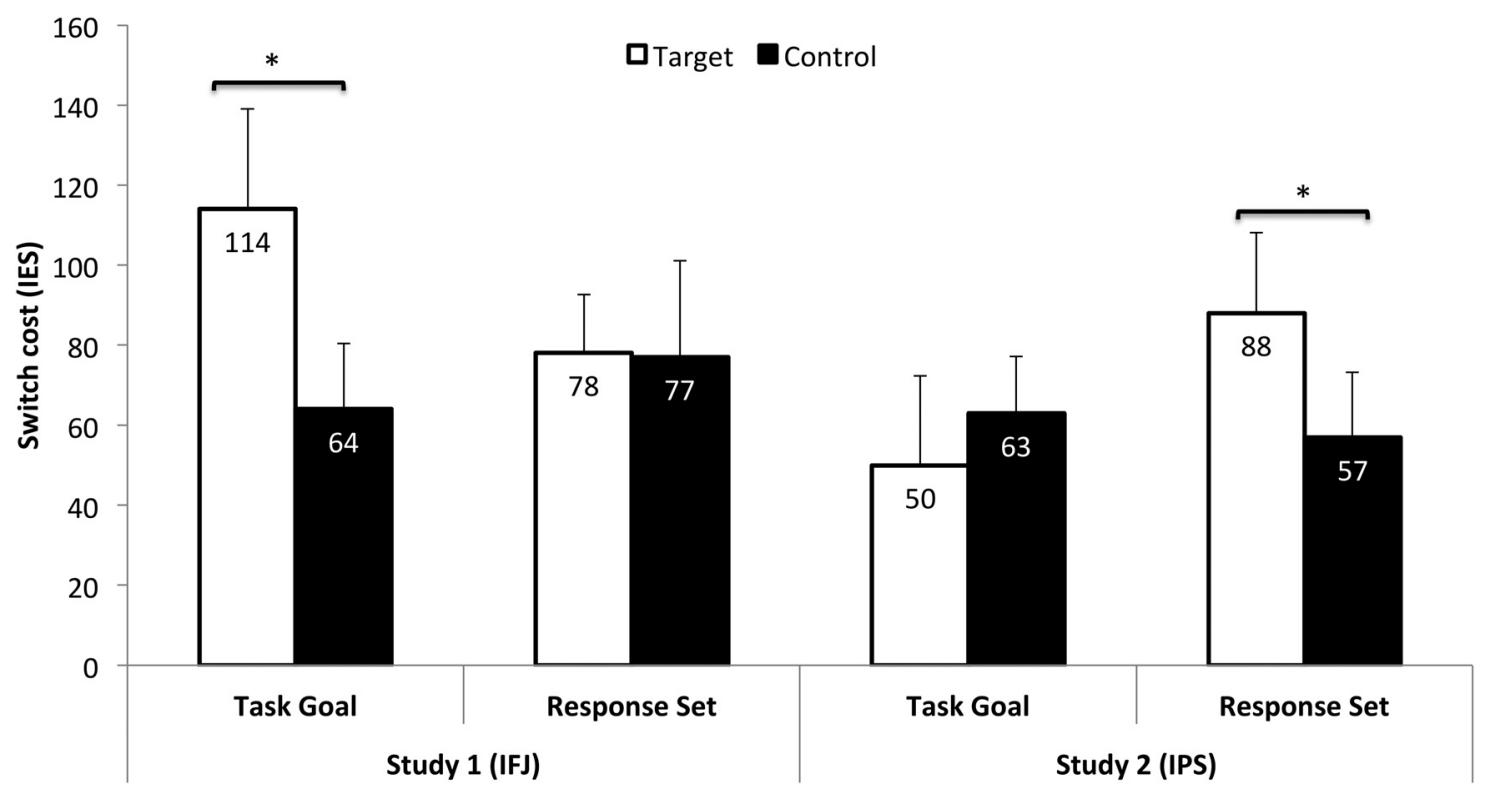

Figure 4. Pooled analysis of results across Experiments 1 and 2. Performance on each block type is expressed as difference between switch trials and repetition trials using IES to integrate speed and accuracy into a single measure. IESs are computed by dividing the reaction time of a design cell by the percentage of correct responses. Note: The displayed values are means and SEs. Asterisks indicate significant differences in switch costs between target site and control site stimulation.

A

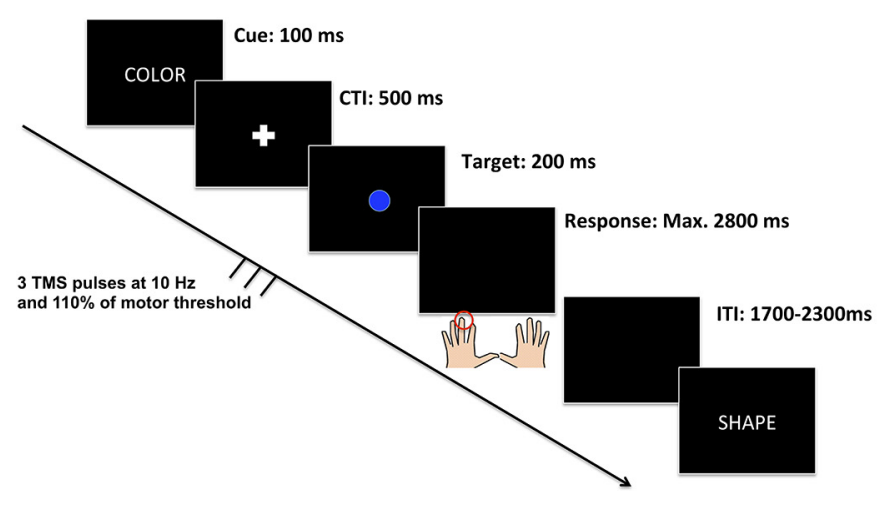

B
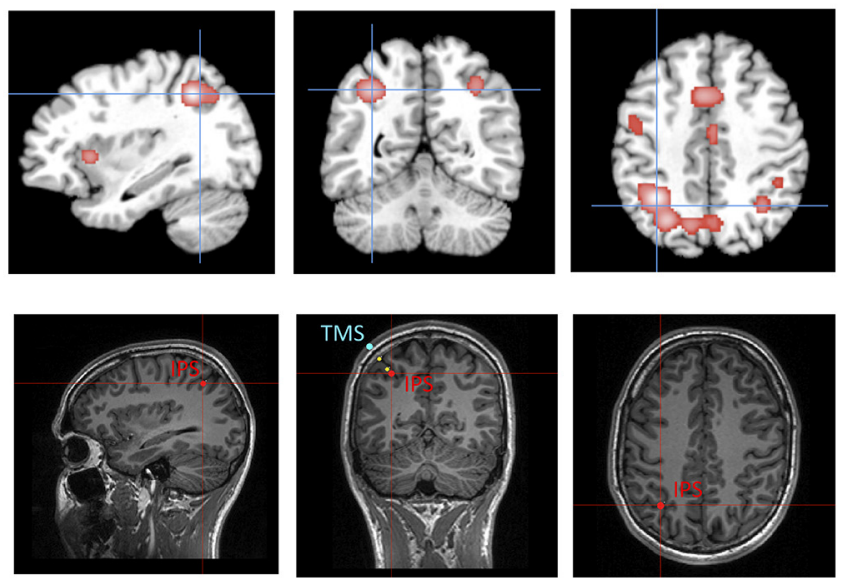

Figure 5. Illustration of the setup of Experiment 3 . Single-trial structure of the experimental paradigm (A). In this experiment, participants completed only TGBs using their left and right middle fingers throughout all blocks. The TMS pulses were time-locked to the onset of the target stimulus to affect the final preparation stages. To avoid stimulation at the time of a response, the number of pulses was reduced to three pulses. Localization of the parietal target site ( $\boldsymbol{B}$ ) was identical as to Experiment 2 (MNI coordinate: $-34,-56,43$ ). The coronal sections of the bottom also display the position of the coil center, where the magnetic field is maximal, relative to the subject's skull (blue markers). Yellow spheres indicate the direction of the current flow (distance between two spheres $=1 \mathrm{~cm}$ ). The average distance between the skull and the target site was $2.41 \mathrm{~cm}$ across participants. Note that the application of TMS trains also affects the brain tissue between the skull and the target site.

be postponed until the onset of the target stimulus. Under this assumption, TMS over the IPS may not have affected performance in TGBs because the critical processes took place outside the CTI after goal setting. This hypothesis was addressed in Experiment 3. Its goal was to examine whether TMS over the left IPS would interfere with task goal updating if the pulses were no longer time-locked to the task cue but instead to the target stimulus, i.e., when the translation of goals into SR rules is required (Fig. 5; See Materials and Methods for details on the procedure).

RTs and error rates were analyzed using repeated-measures ANOVAs with the factors STIMULATION SITE (IPS vs CTR) and TRANSITION (repeat vs switch). An effect of the IPS stimulation on task goal updating should be reflected in a significant interaction between the two factors. The RT analysis revealed a significant main effect of TRANSITION $\left(F_{(1,16)}=12.337, p=\right.$ $0.003)$, reflecting increased RTs on switch trials compared with repetition trials (Fig. $6 A$ ). The main effect of STIMULATION $\operatorname{SITE}\left(F_{(1,16)}=0.285, p=0.601\right)$ and the interaction term $\left(F_{(1,16)}\right.$ $=0.548, p=0.470)$ were both nonsignificant. The analysis of error rates revealed a significant main effect of TRANSITION $\left(F_{(1,16)}=22.144, p<0.001\right)$, reflecting the presence of switch costs, and a marginally significant main effect of STIMULATION $\operatorname{SITE}\left(F_{(1,16)}=3.594, p=0.076\right)$. Most importantly, the interaction between the two factors was significant $\left(F_{(1,16)}=9.918, p=\right.$ 0.006 ; IPS $=5.6 \%$; CTR $=3 \%$; Fig. 5 ). To specify this interaction, we compared switch costs with stimulation of the IPS and stimulation of the control site, revealing that switch costs were indeed enhanced with IPS stimulation $\left(t_{(16)}=3.149\right.$; corrected $p=$ 

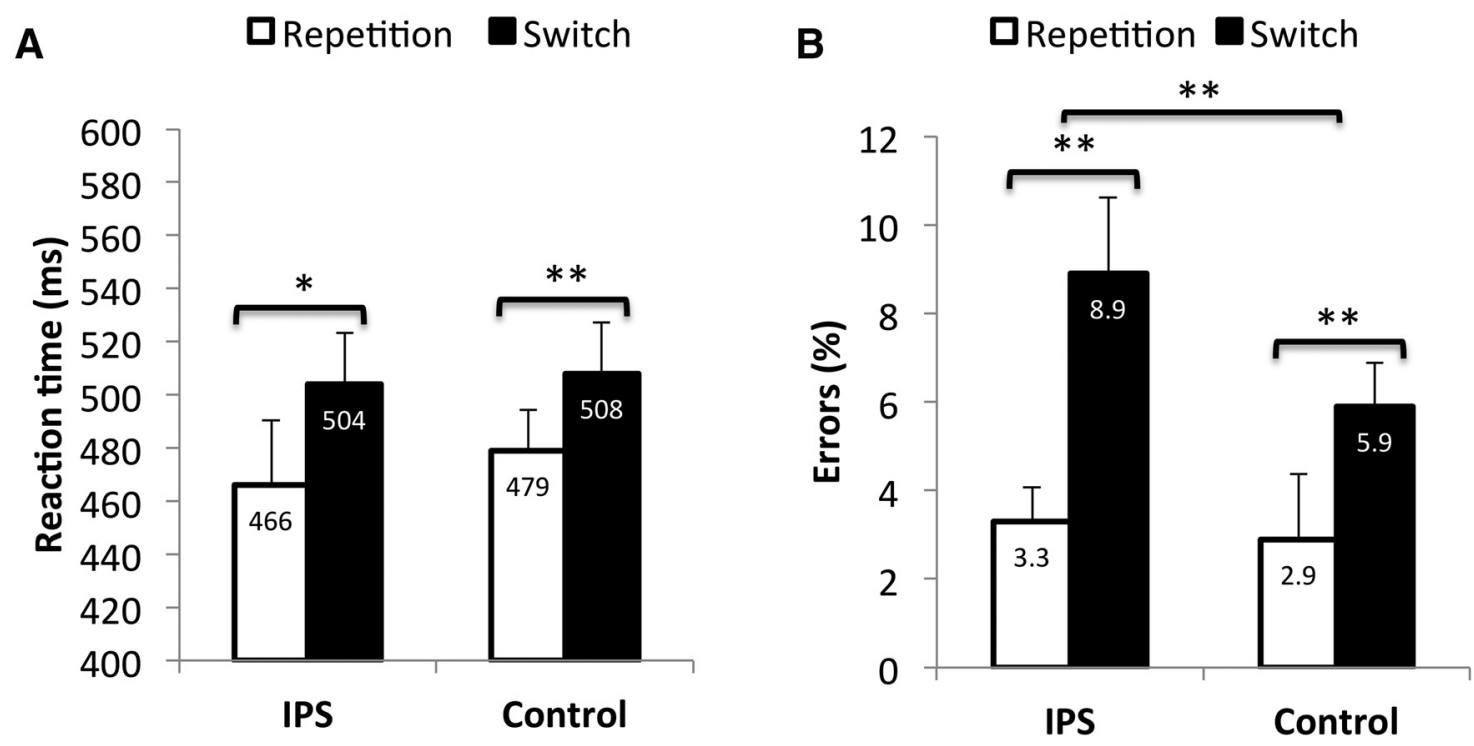

Figure 6. Reaction times $(\boldsymbol{A})$ and error rates $(\boldsymbol{B})$ of Experiment 3 as a function of target site and trial transition. Asterisks indicate significant differences in switch costs with stimulation of the target site and stimulation of the control site. Note: The displayed values are means and within-subject confidence intervals (calculated according to Loftus and Massen, 1994).

0.006; Fig. 6B). This result suggests that TMS over the IPS is also capable of causing interference with task goal updating, but the critical time window occurs later than with TMS over the IFJ, likely reflecting the delayed specification of response sets after goal setting.

\section{Discussion}

In the present study, we investigated the disruptive effects of TMS over the IFJ and the IPS on abstract and action-related preparation processes in humans. In line with our predictions, TMS over the IFJ selectively interfered with the ability to update abstract rules for stimulus categorization. By contrast, TMS over the IPS interfered with the capacity to switch between different action rules within a given task. These findings are consistent with a top-down view on cognitive control in which the PFC biases processing in posterior areas in favor of task goals. Yet, given the increasing evidence that TMS impacts not only the stimulated target region but also functionally connected areas (Feredoes et al., 2011; Zanto et al., 2011; Zandbelt et al., 2013), our findings should be viewed as reflecting the existence of distinct networks for the setting of task goals and response sets, connected to the left IFJ and the left IPS respectively.

\section{IFJ and the setting of task goals}

Our finding that TMS over the IFJ interfered with the setting of new task goals is concordant with various theories of PFC function that consider goal representations within the lateral PFC as the source of top-down signals directed toward posterior cortices (Miller and Cohen, 2001; Bunge, 2004; Fuster, 2008; Passingham and Wise, 2012; Sreenivasan et al., 2014). Interestingly, these theories differ with regard to the representational depth that they ascribe to the PFC. For instance, Miller and Cohen (2001) proposed in their guided-activation theory that prefrontal activity reflects the maintenance of goals and the means for their achievement. Passingham and Wise (2012), on the other hand, emphasized the abstract nature of prefrontal goal representations and stressed that the means for their achievement are specified further downstream in the processing hierarchy. The dissociation of goal setting and rule activation in our study clearly favors a distinction between goal representations themselves and the representations of their behavioral implications.
This view is furthermore supported by recent work on the implementation of verbally instructed behavior. Hartstra et al. (2011) asked participants to implement different types of symbolic instructions (i.e., either mappings of stimuli to responses or mappings of different stimulus attributes) that were either new or practiced before the experiment. It was found that the left IFJ represented new instructions regardless of their type, whereas the bilateral intraparietal sulci were specifically involved in the preparation of SR mappings, regardless of their novelty. This indicates that rule-guided behavior might rely on the interplay between domain-general goal representations in the PFC and modalityspecific brain areas in posterior cortices that are involved in rule implementation. Such a distinction is also in accord with recent single-cell recordings in macaque monkeys during visual categorization tasks (Merchant et al., 2011; Goodwin et al., 2012; Crowe et al., 2013). For instance, Goodwin et al. (2012) recorded simultaneously from neurons in the principal and intraparietal sulci and found that the former exhibited earlier and stronger coding of rule-dependent categories than the latter. Furthermore, Crowe et al. (2013) recently demonstrated that signals about upcoming task rules are transmitted unidirectionally from prefrontal to parietal neurons, possibly reflecting a single-cell substrate of the transformation of abstract goals into specific action rules.

An open issue pertains to the exact mechanism through which the IFJ and its network exert control over novel task goals. One likely candidate is the top-down modulation of the preparatory activation levels in category-specific sensory cortices. Previous studies have shown that effective preparation is associated with regulatory adjustments in extrastriate visual areas that are implicated in processing task-relevant visual information (Wylie et al., 2006; Yeung et al., 2006). Connectivity analyses have identified the IFJ as source of such feature-based top-down modulations (Zanto et al., 2010; Baldauf and Desimone, 2014), and TMS over the IFJ results in diminished category selectivity in visual cortex, which is moreover predictive of subsequent performance impediment in a working-memory task (Zanto et al., 2011; Lee and D'Esposito, 2012). Accordingly, it is reasonable to assume that the IFJ is part of a neural network that facilitates updating of task goals via anticipatory adjustments in task-specific neural circuitries. 


\section{IPS and the activation of response sets}

The results of Experiments 2 and 3 shed new light on the contribution of the left IPS to preparatory control. In previous work, the IPS has been ascribed a prominent role in sensorimotor transformations (Andersen and Buneo, 2002; Cohen and Andersen, 2002), connecting cognitive, perceptual, and motor codes (Gottlieb, 2007). The left IPS in particular has been linked with motor aspects of cognition such as motor attention (Rushworth et al., 2001), effector choice (Cui and Andersen, 2007, 2011), and action intentions (Hamilton and Grafton, 2006). Based on these findings, it has been proposed that the left IPS constitutes the top of the motor hierarchy, presumably via projections to the premotor cortex where, in turn, a specific motor program is selected (Tunik et al., 2005, 2007; Rice et al., 2006; Davare et al., 2010; Taubert et al., 2010). These considerations fit well with our conclusion that the IPS and its network are involved in the translation of abstract task goals into specific action rules to guide task implementation upon the appearance of a target stimulus. The results of Experiment 3 further substantiated this view by indicating that TMS over this region can also cause interference with task goal updating, but that the critical time window occurs later than with IFJ stimulation, namely when the specification of response sets is required. This study also replicated our observation that parietal TMS affected performance at the level of accuracy. This is consistent with our view that the IPS and its network contribute to stages of preparation that are proximate to task implementation. Accordingly, TMS over this region may lead to direct confusion of response sets, resulting in inaccurate rather than delayed performance.

Applying TMS at different time points may generally offer a promising approach for future research to fully characterize the crosstalk between frontoparietal areas during task preparation. For instance, the IFJ and the IPS could both be stimulated at different timings within the same group of participants. Moreover, combining TMS with additional imaging methods may help to reveal the neural mechanisms that mediate behavioral effects of TMS (Taylor et al., 2007; Feredoes et al., 2011; Higo et al., 2011; Zanto et al., 2011, 2013).

\section{Implications for cognitive control of human behavior}

Our findings have broad implications given that the distinction between abstract and action-related control components is applicable to a variety of paradigms. For instance, Derrfuss et al. (2004, 2005) argued that interference in the classical Stroop task can similarly be decomposed into a task component (i.e., interference between the goals to name either the ink color or the meaning of a word) and a response component (i.e., interference between the respective responses associated with the ink color and word meaning of a given stimulus). In a similar vein, Rushworth et al. (2002), distinguished between an "attentional set" and an "intentional set" to differentiate cognitive conflict that is induced either by competing stimulus dimensions or by incompatible responseselection rules. Clearly, further research will be necessary to examine the transfer of our findings to other paradigms, yet it is tempting to consider that the interplay of abstract goals and response sets reflects a cardinal principle of cognitive control. This idea is supported by an existing body of research that points to the level of abstraction as a central characteristic in the neural architecture of cognitive control. Since the seminal experiment by Koechlin et al. (2003), numerous studies have indicated that the PFC is organized along a rostral-caudal gradient, with more anterior regions being involved in increasingly higher-order control functions (Badre and D'Esposito, 2007; Badre et al., 2010; Des- met et al., 2011; Kim et al., 2011; Nee and Brown, 2012). Our results thus corroborate the validity of distinguishing cognitive control functions based on their abstraction levels and furthermore highlight that such differences are not only relevant for the organization of the frontal lobe itself, but also for its interaction with other brain areas.

\section{Conclusion}

Our study shows that TMS over prefrontal and parietal cortices has dissociable effects on task preparation in humans. While TMS over the IFJ perturbed the capacity to update the general context of a task episode, TMS over the IPS interfered with the specification of the resulting SR rules. These findings demonstrate that effective task preparation entails distinct types of cognitive control processes and elucidate how prefrontal and parietal cortices may interact in the pursuit of behavioral goals.

\section{References}

Andersen RA, Buneo CA (2002) Intentional maps in posterior parietal cortex. Annu Rev Neurosci 25:189-220. CrossRef Medline

Badre D, D'Esposito M (2007) Functional magnetic resonance imaging evidence for a hierarchical organization of the prefrontal cortex. J Cogn Neurosci 19:2082-2099. CrossRef Medline

Badre D, Kayser AS, D'Esposito M (2010) Frontal cortex and the discovery of abstract action rules. Neuron 66:315-326. CrossRef Medline

Baldauf D, Desimone R (2014) Neural mechanisms of object-based attention. Science 344:424-427. CrossRef Medline

Bode S, Haynes JD (2009) Decoding sequential stages of task preparation in the human brain. Neuroimage 45:606-613. CrossRef Medline

Brass M, von Cramon DY (2004) Decomposing components of task preparation with unctional magnetic resonance imaging. J Cogn Neurosci 16: 609-620. CrossRef Medline

Brass M, Ullsperger M, Knoesche TR, von Cramon DY, Phillips NA (2005) Who comes first? The role of the prefrontal and parietal cortex in cognitive control. J Cogn Neurosci 17:1367-1375. CrossRef Medline

Bruyer R, Brysbaert M (2011) Combining speed and accuracy in cognitive psychology: is the inverse efficiency score (IES) a better independent variable than the mean reaction time (RT) and the percentage of errors $(\mathrm{PE})$ ? Psychol Belg 51:5-13.

Bunge SA (2004) How we use rules to select actions: a review of evidence from cognitive neuroscience. Cogn Affect Behav Neurosci 4:564-579. CrossRef Medline

Bunge SA, Hazeltine E, Scanlon MD, Rosen AC, Gabrieli JD (2002) Dissociable contributions of prefrontal and parietal cortices to response selction. Neuroimage 17:1562-1571. CrossRef Medline

Bunge SA, Wallis JD (2008) Neuroscience of rule-guided behavior. New York: Oxford UP.

Cohen YE, Andersen RA (2002) A common reference frame for movement plans in the posterior parietal cortex. Nat Rev Neurosci 3:553-562. CrossRef Medline

Cole MW, Schneider W (2007) The cognitive control network: integrated cortical regions with dissociable functions. Neuroimage 37:343-360. CrossRef Medline

Crowe DA, Goodwin SJ, Blackman RK, Sakellaridi S, Sponheim SR, Macdonald AW 3rd, Chafee MV (2013) Prefrontal neurons transmit signals to parietal neurons that reflect executive control of cognition. Nat Neurosci 16:1484-1491. CrossRef Medline

Cui H, Andersen RA (2007) Posterior parietal cortex encodes autonomously selected motor plans. Neuron 56:552-559. CrossRef Medline

Cui H, Andersen RA (2011) Different representations of potential and selected motor plans by distinct parietal areas. J Neurosci 31:18130-18136. CrossRef Medline

Davare M, Rothwell JC, Lemon RN (2010) Causal connectivity between the human anterior intraparietal area and premotor cortex during grasp. Curr Biol 20:176-181. CrossRef Medline

Dehaene S, Kerszberg M, Changeux JP (1998) A neuronal model of global workspace in effortful cognitive tasks. Proc Natl Acad Sci U S A 95: 14529-14534. CrossRef Medline

Del Gratta C, Della Penna S, Ferretti A, Franciotti R, Pizzella V, Tartaro A, Torquati K, Bonomo L, Romani GL, Rossini PM (2002) Topographic organization of the 
human primary and secondary somatosensory cortices: comparison of fMRI and meg findings. Neuroimage 17:1373-1383. CrossRef Medline

Derrfuss J, Brass M, von Cramon DY (2004) Cognitive control in the posterior frontolateral cortex: evidence from common activations in task coordination, interference control, and working memory. Neuroimage 23:604-612. CrossRef Medline

Derrfuss J, Brass M, Neumann J, von Cramon DY (2005) Involvement of the inferior frontal junction in cognitive control: meta-analyses of switching and Stroop studies. Hum Brain Mapp 25:22-34. CrossRef Medline

Desmet C, Fias W, Hartstra E, Brass M (2011) Errors and conflict at the task level and the response level. J Neurosci 31:1366-1374. CrossRef Medline

Duncan J (2010) The multiple-demand (MD) system of the primate brain: mental programs for intelligent behaviour. Trends Cogn Sci 14:172-179. CrossRef Medline

Eickhoff SB, Laird AR, Grefkes C, Wang LE, Zilles K, Fox PT (2009) Coordinate-based activation likelihood estimation meta-analysis of neuroimaging data: a random-effects approach based on empirical estimates of spatial uncertainty. Hum Brain Mapp 30:2907-2926. CrossRef Medline

Eickhoff SB, Bzdok D, Laird AR, Kurth F, Fox PT (2012) Activation likelihood estimation meta-analysis revisited. Neuroimage 59:2349-2361. CrossRef Medline

Feredoes E, Heinen K, Weiskopf N, Ruff C, Driver J (2011) Causal evidence for frontal involvement in memory target maintenance by posterior brain areas during distracter interference of visual working memory. Proc Natl Acad Sci U S A 108:17510-17515. CrossRef Medline

Fuster JM (2008) The prefrontal cortex, Ed 4. London: Academic.

Goodwin SJ, Blackman RK, Sakellaridi S, Chafee MV (2012) Executive control over cognition: stronger and earlier rule-based modulation of spatial category signals in prefrontal cortex relative to parietal cortex. J Neurosci 32:3499-3515. CrossRef Medline

Gottlieb J (2007) From thought to action: the parietal cortex as a bridge between perception, action, and cognition. Neuron 53:9-16. CrossRef Medline

Hamilton AF, Grafton ST (2006) Goal representation in human anterior intraparietal sulcus. J Neurosci 26:1133-1137. CrossRef Medline

Hartstra E, Kühn S, Verguts T, Brass M (2011) The implementation of verbal instructions: an fmri study. Hum Brain Mapp 32:1811-1824. CrossRef Medline

Higo T, Mars RB, Boorman ED, Buch ER, Rushworth MF (2011) Distributed and causal influence of frontal operculum in task control. Proc Natl Acad Sci U S A 108:4230-4235. CrossRef Medline

Jamadar S, Hughes M, Fulham WR, Michie PT, Karayanidis F (2010) The spatial and temporal dynamics of anticipatory preparation and response inhibition in task-switching. Neuroimage 51:432-449. CrossRef Medline

Kim C, Johnson NF, Cilles SE, Gold BT (2011) Common and distinct mechanisms of cognitive flexibility in prefrontal cortex. J Neurosci 31:47714779. CrossRef Medline

Koechlin E, Ody C, Kouneiher F (2003) The architecture of cognitive control in the human prefrontal cortex. Science 302:1181-1185. CrossRef Medline

Lee TG, D'Esposito M (2012) The dynamic nature of top-down signals originating from prefrontal cortex: a combined fMRI-TMS study. J Neurosci 32:15458-15466. CrossRef Medline

Loftus GR, Massen ME (1994) Using confidence intervals in within-subject designs. Psychon Bull Rev 1:476-490. CrossRef Medline

Merchant H, Crowe DA, Robertson, MS, Fortes AF, Georgopoulos AP (2011) Top-down spatial categorization signal from prefrontal to posterior parietal cortex in the primate. Front Syst Neurosci 5:69. CrossRef Medline

Miller EK, Cohen JD (2001) An integrative theory of prefrontal cortex function. Annu Rev Neurosci 24:167-202. CrossRef Medline

Monsell S (2003) Task switching. Trends Cogn Sci 7:134-140. CrossRef Medline

Nee DE, Brown JW (2012) Rostral-caudal gradients of abstraction revealed by multi-variate pattern analysis of working memory. Neuroimage 63: 1285-1294. CrossRef Medline

Nieuwenhuis S, Forstmann BU, Wagenmakers EJ (2011) Erroneous analyses of interactions in neuroscience: a problem of significance. Nat Neurosci 14:1105-1107. CrossRef Medline

Passingham RE, Wise SP (2012) The neurobiology of the prefrontal cortex: anatomy, evolution, and the origin of insight. Oxford: Oxford UP.

Philipp AM, Weidner R, Koch I, Fink GR (2013) Differential roles of inferior frontal and inferior parietal cortex in task switching: evidence from stimulus-categorization switching and response-modality switching. Hum Brain Mapp 34:1910-1920. CrossRef Medline
Rice NJ, Tunik E, Grafton ST (2006) The anterior intraparietal sulcus mediates grasp execution, independent of requirement to update: new insights from transcranial magnetic stimulation. J Neurosci 26:8176-8182. CrossRef Medline

Rossi S, Hallett M, Rossini PM, Pascual-Leone A (2009) Safety, ethical considerations, and application guidelines for the use of transcranial magnetic stimulation in clinical practice and research. Clin Neurophysiol 120:2008-2039. CrossRef Medline

Ruben J, Schwiemann J, Deuchert M, Meyer R, Krause T, Curio G, Villringer K, Kurth R, Villringer A (2001) Somatotopic organization of human secondary somatosensory cortex. Cereb Cortex 11:463-473. CrossRef Medline

Rubinstein JS, Meyer DE, Evans JE (2001) Executive control of cognitive processes in task switching. J Exp Psychol Hum Percept Perform 27:763797. CrossRef Medline

Ruge H, Jamadar S, Zimmermann U, Karayanidis F (2013) The many faces of preparatory control in task switching: reviewing a decade of fMRI research. Hum Brain Mapp 34:12-35. CrossRef Medline

Rushworth MF, Ellison A, Walsh V (2001) Complementary localization and lateralization of orienting and motor attention. Nat Neurosci 4:656-661. CrossRef Medline

Rushworth MF, Hadland KA, Paus T, Sipila PK (2002) Role of the human medial frontal cortex in task switching: a combined fMRI and TMS study. J Neurophysiol 87:2577-2592. Medline

Sreenivasan KK, Curtis CE, D'Esposito M (2014) Revisiting the role of persistent neural activity during working memory. Trends Cogn Sci 18:82-89. CrossRef Medline

Swaminathan SK, Freedman DJ (2012) Preferential encoding of visual categories in parietal cortex compared with prefrontal cortex. Nat Neurosci 15:315-320. CrossRef Medline

Taubert M, Dafotakis M, Sparing R, Eickhoff S, Leuchte S, Fink GR, Nowak DA (2010) Inhibition of the anterior intraparietal area and the dorsal premotor cortex interfere with arbitrary visuo-motor mapping. Clin Neurophysiol 121:408-413. CrossRef Medline

Taylor PC, Nobre AC, Rushworth MF (2007) Subsecond changes in top down control exerted by human medial frontal cortex during conflict and action selection: a combined transcranial magnetic stimulation electroencephalography study. J Neurosci 27:11343-11353. CrossRef Medline

Townsend JT, Ashby FG (1983) Stochastic modelling of elementary psychological processes. Cambridge: Cambridge UP.

Tunik E, Frey SH, Grafton ST (2005) Virtual lesions of the anterior intraparietal area disrupt goal-dependent on-line adjustments of grasp. Nat Neurosci 8:505-511. CrossRef Medline

Tunik E, Rice NJ, Hamilton A, Grafton ST (2007) Beyond grasping: representation of action in human anterior intraparietal sulcus. Neuroimage 36:T77-T86. CrossRef Medline

Walsh V, Cowey A (2000) Transcranial magnetic stimulation and cognitive neuroscience. Nat Rev Neurosci 1:73-79. Medline

Woolgar A, Hampshire A, Thompson R, Duncan J (2011) Adaptive coding of task-relevant information in human frontoparietal cortex. J Neurosci 31:14592-14599. CrossRef Medline

Wylie GR, Javitt DC, Foxe JJ (2006) Jumping the gun: is effective preparation contingent upon anticipatory activation in task-relevant neural circuitry? Cereb Cortex 16:394-404. CrossRef Medline

Yeung N, Nystrom LE, Aronson JA, Cohen JD (2006) Between-task competition and cognitive control in task switching. J Neurosci 26:1429-1438. CrossRef Medline

Zandbelt BB, Bloemendaal M, Hoogendam JM, Kahn RS, Vink M (2013) Transcranial magnetic stimulation and functional MRI reveal cortical and subcortical interactions during stop-signal response inhibition. J Cogn Neurosci 25:157-174. CrossRef Medline

Zanto TP, Rubens MT, Bollinger J, Gazzaley A (2010) Top-down modulation of visual feature processing: the role of the inferior frontal junction. Neuroimage 53:736-745. CrossRef Medline

Zanto TP, Rubens MT, Thangavel A, Gazzaley A (2011) Causal role of the prefrontal cortex in top-down modulation of visual processing and working memory. Nat Neurosci 14:656-661. CrossRef Medline

Zanto TP, Chadick JZ, Satris G, Gazzaley A (2013) Rapid functional reorganiation in human cortex following neural pertubation. J Neurosci 33: 16268-16274. CrossRef Medline 